DOI: $10.5277 /$ epe 160305

\title{
MICROBIAL COMMUNITIES AND RELATIONSHIP WITH BIOFILM SPATIAL DISTRIBUTIONS IN SUBSURFACE WASTEWATER INFILTRATION SYSTEMS
}

\begin{abstract}
A pilot-scale subsurface wastewater infiltration system (SWIS) was designed for the treatment of polluted river water. The components of microbial communities have been identified and characterized and their dependences on some indicators of biofilm formation in the SWIS have been determined. The average efficiencies of COD, TN and $\mathrm{NH}_{4}^{+}-\mathrm{N}$ removal were $43.3 \%, 28.8 \%$ and $79.6 \%$, respectively. According to the denaturing gradient gel electrophoresis (DGGE) profile, high intensity and uniform bands were generated, indicating an abundant microbial community in each layer of the SWIS. Furthermore, the Shannon index analysis showed high correlation to the spatial distribution of microbial communities as well as the quantity of biofilm in each sample, which were characterized by measuring volatile suspended solids (VSS), phospholipids, proteins and polysaccharides. Sequencing of partial 16S rRNA gene fragments revealed that the composition of the total bacterial communities was dominated by Alphaproteobacteria, Gammaproteobacteria, Deltaproteobacteria, Pseudomonas, Bacillus, Flavobacteriaceae, TM-7, and other uncultured bacteria. These bacteria may contribute to nutrient removal in SWIS.
\end{abstract}

\section{INTRODUCTION}

Urban landscape water is commonly polluted by low-concentration organic compounds originating from rainstorm runoff and wastewater discharge [1, 2]. Subsurface wastewater infiltration systems (SWISs) are increasingly used in the treatment of these polluted landscape waters [2,3]. Compared to the conventional activated sludge process, SWISs have many advantages including simplicity in construction, low maintenance costs, and ease of operation [4].

${ }^{1}$ College of Architecture and Environment, Sichuan University, Chengdu 610065, China.

${ }^{2}$ School of Chemistry and Chemical Engineering, Henan University of Technology, Zhengzhou 450001, China, corresponding author J. Yang, e-mail: zlb2863@163.com

${ }^{3}$ College of Environmental Science and Engineering, Tongji University, Shanghai 200092, China. 
Microbial communities in functional SWISs play an important role for the removal of organic pollutants. In order to further study the underlying biological processes involved, the importance of microbial community structures in the water-biofilm-plant system must be determined. In general, microbial populations within SWISs are enumerated using the traditional plate count method [5]. However, more recently, studies utilizing novel molecular biology and genetic techniques have been drawn a great deal of attention, one example of which is polymerase chain reaction followed by denaturing gradient gel electrophoresis (PCR-DGGE) [6].

The superiority of molecular biology applied in studying bacterial communities lies in their entirety without the need to culture the communities. Denaturing gradient gel electrophoresis (DGGE) of PCR amplified 16S rRNA gene fragments [7] and amplified DNA fragment length polymorphism are culture-independent techniques that have been widely used for exploring environmental microbial communities. For example, PCR-DGGE is used to investigate microbial communities in constructed wetland (CW) [8] and other ecological treatment systems [9]. Mina et al. [10] found that the dynamics of microbial communities revealed a high bacterial diversity within $\mathrm{CW}$, with no relevant differences in microbial composition at the inlet and the outlet. Wang et al. [11] concluded that the performance band patterns of microbial community profiles in a novel three-stage vermifiltration (VF) system changed depending on the nature of the matrices and various sampling times.

However, there are only a small number of studies that have been published on the characteristics of bacterial communities by using molecular biology technology and the spatial distributions of bacterial communities within SWISs. These types of studies are important for the determination of biofilm characteristics and their ability to remove pollutants in SWISs. Zhang et al. [3] indicated that a range of parameters, including volatile suspended solid (VSS), proteins, polysaccharides and viable cell number, can be used to follow the biofilm development process in SWIS. VSS relates to biomass growth and represents the non-ash portion of the total suspended solids. To a certain extent, VSS can be used to express the quantity of biofilm present in a system. Protein and polysaccharide are main components of the extracellular polymeric substance (EPS), which helps biofilms attach to surfaces and binds the biofilms together, while protecting the microbial inhabitants from the surrounding environment. These macromolecules are also representative of the quantity of biofilm. Zhang et al. [3] reported the spatial distributions of biofilm properties applying these biofilm parameters in SWIS.

These studies indicate that investigation of the microbial composition and function within a SWIS can help researchers understand and control the biofilm formation process, resulting eventually in an overall optimization of the SWIS. The objective of this study is to evaluate the spatial distribution of microbial community structures and microbial diversity across different sections of a pilot SWIS, with the aim understanding how these properties are related to the ability of a given SWIS to treat contaminated 
river water. Furthermore, the relationships between microbial communities and biofilm characteristics can be explored.

\section{METHODS}

Instrumentation and methods of analysis. Using standard methods provided by Chinese EPA (2002), a colorimetric method was used to quantify $\mathrm{NH}_{4}^{+}-\mathrm{N}, \mathrm{NO}_{3}^{-}-\mathrm{N}^{-} \mathrm{NO}_{2}^{-}-\mathrm{N}$, total nitrogen (TN) and total phosphate (TP). A Merck Spectroquant TR420/NOVA60 COD meter (Germany) was used for COD analysis. Each sample analysis was performed in triplicate.

SWIS characteristics and sampling. A $50 \mathrm{~m}^{2}$ pilot SWIS of the dimensions of $20 \times 2.5 \times 1.0 \mathrm{~m}$ was constructed in a village located on the Chongming Island, Shanghai, China. River water was pumped into distribution pipes located at the bottom of the distributing slot. Treated effluent was collected through collection pipes at the bottom of the pilot system. The whole system was divided into two parts: a water distribution and a filter section. The distribution slot was charged with gravels (particle size 1-2 cm) and the filter was charged with sand (particle size $0.3-1.0 \mathrm{~mm}$, density $2.59 \mathrm{~g} / \mathrm{cm}^{3}$, porosity $42 \%$, specific surface area $0.9361 \pm 0.0025 \mathrm{~m}^{2} / \mathrm{g}$ ). During the experimental period, the system was continuously fed with river water at a hydraulic load of $0.2 \mathrm{~m}^{3} /\left(\mathrm{m}^{2} \cdot\right.$ day $)$.

At the end of the experiment, sixteen samples (Nos. 1-16) were collected from the longitudinal section of the system. The layout of the samples was a $4 \times 4$ square matrix, at level and vertical intervals of $300 \mathrm{~mm}$ and $200 \mathrm{~mm}$, respectively. All results were obtained by averaging three measurements from each sample. During the experiment, samples were stored in sample containers frozen at $-20{ }^{\circ} \mathrm{C}$.

DNA extraction. The culture-dependent method involved DNA extraction from colonies after $96 \mathrm{~h}$ culture grow to identify the microbial composition. Sterilized deionized water $\left(3 \mathrm{~cm}^{3}\right)$ was used to wash colonies in each plate and DNA extraction was performed by using alkaline lysis [12]. DNA extraction was performed within $24 \mathrm{~h}$ of sampling for culture-independent procedure. A FastDNA ${ }^{\circledR}$ SPIN Kit for soil was used for DNA extraction from $0.5 \mathrm{~g}$ of fillers sample according to the manufacturer's instructions (MP Biomedicals, Santa Ana, CA, USA). DNA quality was assessed by agarose gel electrophoresis $(0.8 \%)$ which was stained using ethidium bromide. No additional purification procedure was needed for any of the samples. Subsequently, the purified DNA was stored at $-20{ }^{\circ} \mathrm{C}$ before it was used as a template for PCR amplification.

Polymerase chain reaction. The full-length $16 \mathrm{~S}$ rRNA gene fragment was amplified using universal primers $8 \mathrm{~F}$ and 1492R [13]. PCR amplification was performed under 
the following conditions: initial denaturation at $95^{\circ} \mathrm{C}$ for $4 \mathrm{~min}, 30$ cycles of denaturation at $94{ }^{\circ} \mathrm{C}$ for $30 \mathrm{~s}$, annealing at $65{ }^{\circ} \mathrm{C}$ for $30 \mathrm{~s}$, and extension at $72{ }^{\circ} \mathrm{C}$ for $60 \mathrm{~s}$ followed by a final extension step at $72{ }^{\circ} \mathrm{C}$ for $7 \mathrm{~min}$. The presence of PCR products was confirmed by electrophoresis on $0.8 \%$ agarose gels stained with ethidium bromide.

The second set of PCR amplifications was carried out using the primers 341F-GC and 534R in succession, targeting the V3 region of 16S rRNA [6]. PCR amplification was performed under the following conditions: $95^{\circ} \mathrm{C}$ for $4 \mathrm{~min}, 30$ cycles of denaturation at $94{ }^{\circ} \mathrm{C}$ for $30 \mathrm{~s}$, annealing at $58^{\circ} \mathrm{C}$ for $30 \mathrm{~s}$ and extension at $72{ }^{\circ} \mathrm{C}$ for $60 \mathrm{~s}$ followed by a final extension step at $72{ }^{\circ} \mathrm{C}$ for $10 \mathrm{~min}$. The presence of PCR products was confirmed by electrophoresis on $0.8 \%$ agarose gels stained with ethidium bromide.

Denaturing gradient gel electrophoresis. A DCode Universal Mutation Detection System (Bio-Rad, USA) was used to perform DGGE analysis. PCR products were loaded onto $10 \%$ (wt/vol) polyacrylamide (37.5:1, acrylamide: bisacrylamide) gels with a linear denaturing gradient from 40 to $60 \%$ (100\% denaturant was a mixture of $7 \mathrm{M}$ urea and $40 \%$ deionized formamide). Electrophoresis was performed in $1 \times \mathrm{TAE}$ buffer and allowed to proceed for $5.5 \mathrm{~h}$ at $200 \mathrm{~V}$ and $60^{\circ} \mathrm{C}$. Gels were stained with ethidium bromide solution and images were captured using a Bio-Rad gel documentation system (Bio-Rad, USA).

Analysis of DGGE patterns. DGGE patterns were analyzed using Quantity One 4.1 software (Bio-Rad, USA). Similarity matrices and dendrogram of the DGGE profiles were generated using the Pearson correlation coefficients and unweighted pair-group method average (UPGMA), respectively. The structural diversity of the microbial community was expressed using the Shannon index of general diversity $(H)$ [14]. $H$ was calculated based on peak height from various bacterial groups (16S rDNA bands).

The Shannon index is expressed as

$$
H=-\sum_{i=1}^{s} \frac{n_{i}}{N} \ln \frac{n_{i}}{N}
$$

where $n_{i}$ is the height of the peak, $N$ is the sum of all peak heights of the densitometric curve, and $s$ is the number of the bands. The richness of the microbial community was determined using the number of bands in each lane. Statistical analysis was performed by applying the general linear model (GLM) procedure of the SAS software 9.1 (SAS Institute, Inc., Cary, NC, USA).

Cloning of PCR products and sequencing. The target DGGE bands were excised and rinsed three times using $0.001 \mathrm{~cm}^{3}$ sterile deionized water. Each gel fragment was crushed with a pipette tip and DNA was dissolved in $0.0001 \mathrm{~cm}^{3}$ of sterile deionized water at $-20{ }^{\circ} \mathrm{C}$ overnight. PCR amplification was performed with the primers $341 \mathrm{~F}$ 
(without a GC clamp) and $534 \mathrm{R}$. The PCR products were cloned into a pMD18-T vector (TaKaRa, Dalian, China) and sequenced by Invitrogen China (Shanghai, China).

\subsection{PHYLOGENETIC ANALYSIS}

Sequences were analyzed using a BLAST search of the NCBI nucleotides sequence database (http://blast.ncbi.nlm.nih.gov/Blast.cgi). For phylogenetic analysis, sequences were aligned with Clustal X. A phylogenetic tree was constructed using MEGA 5.0, and reference sequences used for tree construction were acquired from the GenBank. DNA sequences were subjected to the Classifier and Sequence Match programs of the Ribosomal Database Project (RDP) II (http://rdp.cme.msu.edu). The 20 nucleotide sequences reported in this study have been deposited into the GenBank database.

Quantification of biofilm components. The total number of viable cell was approximated using the measured quantity of phospholipids. Extraction of phospholipids and release of phosphates were performed by the method of Findlay et al. [15]. Phosphate concentration was then correlated to viable biomass using the conversion factor, $1 \mathrm{nmol}$ phosphate is proportional to $3.4 \times 10^{7}$ cells [15].

Extracellular polymeric substances (EPSs) can arise from natural bacterial secretory processes, cell lysis and hydrolysis [16]. EPS include a rich matrix of biopolymers, polysaccharides and proteins are two main constituents of EPSs. EPS extraction was performed by the method modified from those reported by Liu and Fang [17]. The determination methods have been previously described by Zhang et al. [3].

Data analysis. The isoline of the Shannon index spatial distribution was drawn using Surfer 8.0. In addition, statistical analyses, including Pearson and Spearman's rank correlations, were carried out using SPSS 14.0 (SPSS, Inc., America). The Pearson correlation coefficient $\left(r_{p}\right)$ was used to estimate linear correlations, where 1 means a perfect positive correlation, -1 signifies a perfect negative correlation, and 0 indicates an absence of relationship. Correlations were considered statistically significant at a $99 \%$ confidence interval $(P<0.01)$.

\section{RESULTS AND DISCUSSION}

\subsection{OVERALL PILOT SYSTEM PERFORMANCE}

During the operational period, the efficiency of COD removal ranged from 5 to $74 \%$, with a mean of $43.3 \%$. Due to the low concentration of organic matter, BOD/COD value, and low organic loading, the efficiency of COD removal was not very high. In fact, the SWIS could achieve higher COD removal efficiency with a higher organic loading. The removal efficiencies of $\mathrm{TN}$ and $\mathrm{NH}_{4}^{+}-\mathrm{N}$ were also investigated in this study, 
and the measured efficiencies of TN and $\mathrm{NH}_{4}^{+}-\mathrm{N}$ were $0.6-88.9 \%$ and $23.0-100 \%$, respectively, with average removal efficiencies of $28.8 \%$ for $\mathrm{TN}$ and $79.6 \%$ for $\mathrm{NH}_{4}^{+}-\mathrm{N}$ (Table 1).

Table 1

Operation performance of SWIS for river water treatment

\begin{tabular}{|l|c|c|c|}
\hline \multicolumn{1}{|c|}{ Parameter } & Organic matter & Total nitrogen & NH4-N \\
\hline Influent, $\mathrm{mg} / \mathrm{dm}^{3}$ & $14-62(40 \pm 2.8)$ & $1.1-10(3.9 \pm 0.4)$ & $0.13-6.6(1.44 \pm 0.50)$ \\
\hline Effluent, $\mathrm{mg} / \mathrm{dm}^{3}$ & $11-46(21.8 \pm 1.60)$ & $0.12-7.2(3.0 \pm 0.3)$ & $0-1.1(0.2 \pm 0.1)$ \\
\hline Reduction, \% & $5-74(43.3 \pm 6.20)$ & $0.6-88.9(28.8 \pm 6.90)$ & $23-100(79.6 \pm 15.0)$ \\
\hline
\end{tabular}

In SWISs, the environment around the filler is crucial for the metabolism of microorganisms. Therefore, oxidation-reduction potential (ORP) was used to express the redox environment around the filler in this study. The ORP reflects the concentrations of DO, organic substrates, and some toxic compounds, as well as the activity of the microorganisms in the reactor system [18]. In the pilot SWIS, the ORP decreased gradually from $308.1 \mathrm{mV}$ in the top left section to $268.3 \mathrm{mV}$ in the bottom right section. An ORP greater than $100 \mathrm{mV}$ is commonly interpreted to as an aerobic environment [19]. In addition, the concentration of inlet nitrates ranged from 0.28 to $2.40 \mathrm{mg} / \mathrm{dm}^{3}$, compared to the concentration of outlet nitrates, which changed from 2.05 to $3.85 \mathrm{mg} / \mathrm{dm}^{3}$. The concentration of inlet nitrites ranged from 0.044 to $0.11 \mathrm{mg} / \mathrm{dm}^{3}$, higher than the concentration of outlet nitrites, which ranged from 0.001 to $0.002 \mathrm{mg} / \mathrm{dm}^{3}$. In the SWIS, the concentration of nitrites was lower, and due to the aerobic environment around filter, the nitrites were oxidized into nitrates. Nitrification in the aerobic environment explains the concentration gradients of nitrates and nitrites from inlet to outlet in the pilot SWIS.

Because the environment within the pilot SWIS was favorable for nitrification, the efficiency of $\mathrm{NH}_{4}^{+}-\mathrm{N}$ removal was high. Achak et al. [20] concluded similarly that the removal rate of $\mathrm{NH}_{4}^{+}-\mathrm{N}$ can reach $97 \%$ when a sand filter is applied to treat olive mill wastewater. Although the pilot SWIS provides a preferable environment for nitrification, it was not able to create suitable environment for denitrification. Because of poor anaerobic environment and carbon source deficiency at the bottom of system, the removal efficiency of $\mathrm{TN}$ requires additional improvements.

\subsection{DIVERSITY OF MICROBIAL COMMUNITY BASED ON PCR-DGGE}

The microbial diversity of all samples was evaluated by the DGGE analysis of the amplified partial 16S rRNA genes. Some regularities of 16S rRNA patterns were observed throughout the pilot SWIS (Fig. 1). The DGGE profiles showed the uniform and concentrated bands on the electropherogram that were attributed to the abundant microbial community in each layer of the SWIS. 


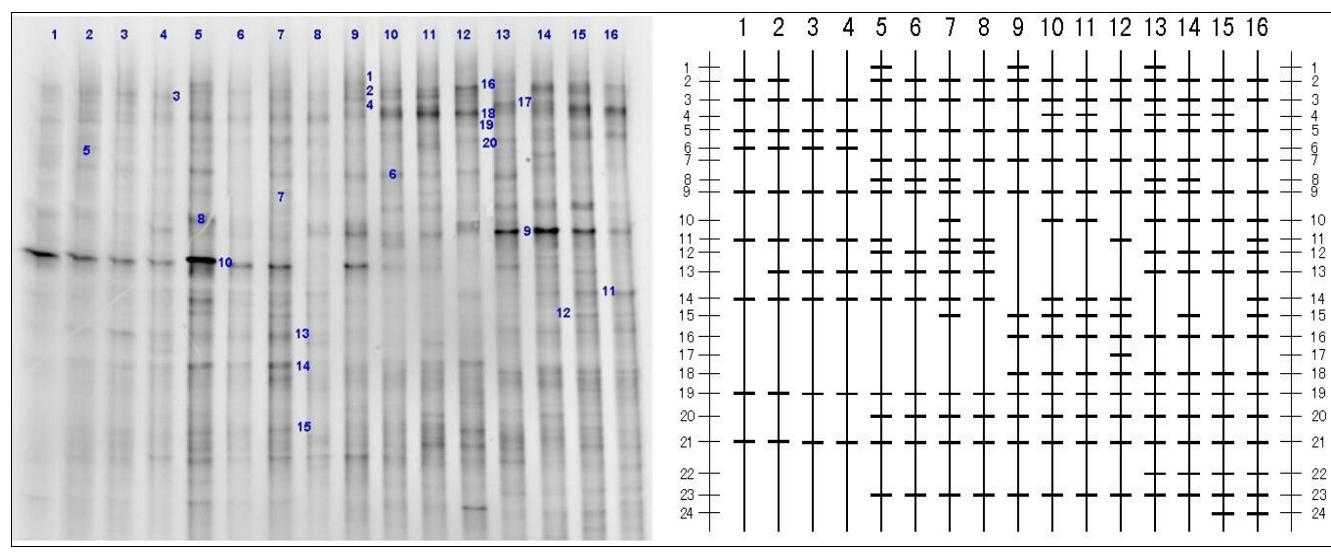

Fig. 1. DGGE profile of bacterial 16S rRNA fragments of total bacterial population from SWIS samples. The numbers 1-20 indicate that the bands were successfully amplified and sequenced

The number of bands in samples 9-16 (the lower layer fillers) ranged from 33 to 57, appreciably more than the number of bands in samples 1-8 (the upper layer fillers), which ranged from 17 to 47 . The distribution regularities were in accordance with the quantities of biofilms, which is in line with observation made by Zhang et al. [3]. The differences in the number of bands between upper and lower layer fillers are likely due to the accumulation of organic matter, which maximized VSS and phospholipids at the bottom of the SWIS. Assuming an even water distribution, the larger number of bands were present in the upper layer fillers than the lower layer fillers, the latter of which may contain an insufficient supply of nutriments, preventing microorganism growth. In addition, the location, intensity, and number of bands were different across the different filler samples from the SWIS. Bands of higher intensities were observed in every sample, suggesting certain dominant species at various locations in the system. For instance, bands 16,17 and 18 were brighter than others bands in samples 9-16, which showed that the species in the former were dominant. On the contrary, the bands 10,14 and 15 were brighter than bands in samples $1-8$, which showed that the species were dominant in upper layer fillers.

The reason we observed dominance of certain species over others may be because different microbial species thrive under different ecological conditions. Certain species transitioned from dominant to non-dominant to non-existent through the different sample layers, due to their sensitivity to the changes in environmental conditions. Furthermore, according to the DGGE profile, the intensity of the band signals DGGE profile for some certain community showed the similar regularity with quantities of biofilms. For example, the minimum signal intensity observed for band 18 was in the top left section of the system, while the maximum signal intensity was found in the bottom right section. The signal intensity increased gradually from the top left section to the bottom right, which linked to the quantity of biofilm in each of these sections. 


\subsection{SHANNON INDEX ANALYSIS AND CORRELATION WITH THE QUANTITIES OF BIOFILM}

The most fundamental characteristic of SWISs is that their function relies significantly on the metabolism of the microorganisms inside biofilms. Several parameters can be used to measure the quantity of biofilms, such as VSS, protein and polysaccharide, etc. Using these parameters and the Shannon index, it was found that the quantities of biofilms increased horizontally from left to right (Table 2).

Table 2

Shannon index and biofilm parameters

\begin{tabular}{|c|c|c|c|c|c|c|c|}
\hline No. & $\begin{array}{c}\text { Band } \\
\text { quantities }\end{array}$ & $\begin{array}{c}\text { Shannon } \\
\text { index }\end{array}$ & $\begin{array}{c}\text { Aqueous } \\
\text { rate } \\
{[\%]}\end{array}$ & $\begin{array}{c}\text { VSS } \\
{[\mathrm{g} / 100 \mathrm{~g}]}\end{array}$ & $\begin{array}{c}\text { Phospholipids } \\
{[\mathrm{nmol} / \mathrm{g} \text { of filler }]}\end{array}$ & $\begin{array}{c}\text { Protein } \\
{[\mu \mathrm{g} /(\mathrm{g} \text { of filler})]}\end{array}$ & $\begin{array}{c}\text { Polysaccharides } \\
{[\mu \mathrm{g} /(\mathrm{g} \text { of filler) }}\end{array}$ \\
\hline 1 & 17 & 0.69 & 6.26 & 0.92 & 41.4 & 70.7 & 529.3 \\
\hline 2 & 18 & 1.83 & 6.74 & 0.94 & 45.0 & 74.4 & 577.5 \\
\hline 3 & 23 & 2.21 & 7.51 & 0.99 & 50.4 & 82.2 & 634.7 \\
\hline 4 & 42 & 2.97 & 14.1 & 1.06 & 61.0 & 98.0 & 753.9 \\
\hline 5 & 32 & 2.27 & 8.45 & 0.95 & 48.3 & 84.7 & 632.0 \\
\hline 6 & 33 & 2.71 & 10.2 & 1.01 & 52.4 & 96.7 & 676.2 \\
\hline 7 & 41 & 2.99 & 13.4 & 1.11 & 60.2 & 113.0 & 744.3 \\
\hline 8 & 47 & 3.13 & 21.9 & 1.14 & 74.4 & 136.7 & 860.9 \\
\hline 9 & 33 & 2.69 & 12.2 & 1.07 & 57.6 & 123.5 & 704.1 \\
\hline 10 & 36 & 2.84 & 15.2 & 1.18 & 67.2 & 135.7 & 788.8 \\
\hline 11 & 48 & 3.29 & 18.7 & 1.23 & 73.4 & 150.4 & 868.5 \\
\hline 12 & 53 & 3.54 & 25.8 & 1.28 & 84.4 & 172.6 & 1009.9 \\
\hline 13 & 41 & 3.02 & 17.0 & 1.19 & 66.8 & 131.4 & 753.6 \\
\hline 14 & 43 & 3.08 & 20.3 & 1.27 & 74.0 & 148.5 & 876.4 \\
\hline 15 & 50 & 3.44 & 26.5 & 1.31 & 84.0 & 163.5 & 959.7 \\
\hline 16 & 57 & 3.57 & 33.0 & 1.37 & 96.7 & 195.1 & 1109.9 \\
\hline
\end{tabular}

As for VSS and phospholipids, the values ranged from 0.92 to $1.06 \mathrm{~g} /(100 \mathrm{~g}$ of filler) and 41.4 to $61.0 \mathrm{~g} /(\mathrm{g}$ of filler), respectively, in row 1 (the top layer of longitudinal section, from sample 1 to sample 4$)$. However, the VSS and phospholipids values ranged from 1.19 to $1.37 \mathrm{~g} /(100 \mathrm{~g}$ of filler) and 66.8 to $96.7 \mathrm{~g} /(\mathrm{g}$ of filler), respectively, in row 4 (the top layer of longitudinal section from sample 13 to sample 16). Other parameters such as protein and polysaccharides, were similar across all samples. These results confirmed the theoretical operational mechanism of SWIS. Furthermore, the Shannon index showed homologous regularity. $H$ increased from the left to the right in the horizontal direction. The Shannon index ranged from 0.69 to 2.97 for row 1 and from 3.02 to 3.57 for row 4.

On the whole, the Shannon index was lowest in the top left section of the system, while the highest value was found in the bottom right section (Fig. 2). The Shannon 
index increased gradually from the top left to the bottom right, ranging from 0.69 to 3.57. The regularity of the Shannon index distribution in the SWIS was consistent with that of the aqueous rate, VSS, phospholipids, protein and polysaccharides (Fig. 2). It was because that the accumulation of organic matter in water flow reduced to the maximum of several parameters in the bottom with the operation of system [3].
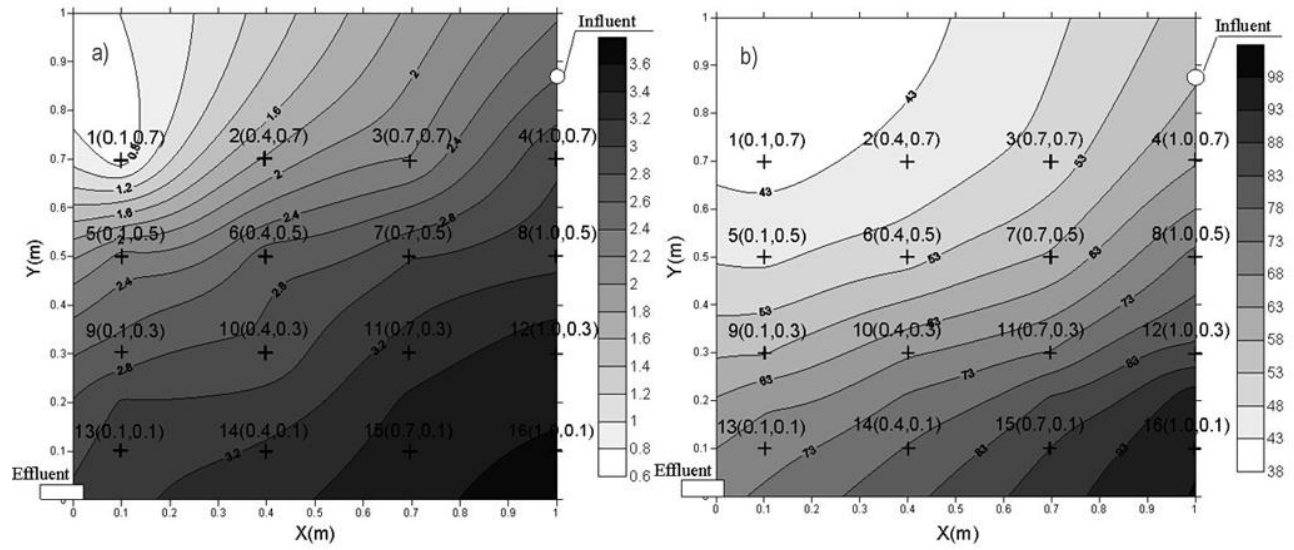

Fig. 2. Spatial distributions of the Shannon index (a) and viable cell number (b) in SWIS

According to Table 2, the lower layer appears to select for highly divergent and distinct biofilm communities, with Shannon indexes ranging from 2.69 to 3.57. These values are higher than those calculated for the upper layer, with Shannon indexes ranging from 0.69 to 3.13. These confirmed the spatial distributions of biofilm quantities further from the microcosmic level.

The spatially dependent diversification of microorganism communities was due to the changes of environmental conditions and nutrition levels. The low aqueous rate in the top left of the system reduced the biofilm quantity, where microorganisms were supplied with insufficient nutrition for metabolism. Consequently, the biodiversity was low in the top left portion of the pilot SWIS. Along the direction of water flow, the presence of ample nutrition resulted in favorable living environments for the growth and proliferation of aerobic and anaerobic microorganisms.

In order to investigate the relationship between the indicators of biofilm quantity including VSS, proteins, polysaccharides, and phospholipids, the correlation analysis has been carried out (Table 3). The indicators were significantly related to the Shannon index. Statistical analysis showed that the Pearson's correlation coefficient $\left(r_{p}\right)$ between either VSS, phospholipids, proteins or polysaccharides and the Shannon index were $0.843,0.856,0.838$ and $0.865(P<0.01)$, respectively. All correlations were statistically significant at a $99 \%$ confidence interval $(P<0.01$, Table 3$)$. These results can be interpreted using the above described spatial distribution (Fig. 2). The accumulation of organic matter in the direction of water flow resulted in the similar trends between the 
indicators of biofilm quantity and the Shannon index. In conclusion, the results in this study confirm the relationship between VSS, phospholipids, proteins, polysaccharides and the Shannon index.

Table 3

Results of the correlation analysis ${ }^{\mathrm{a}}$ between the Shannon index and biofilm parameters

\begin{tabular}{|l|c|c|c|c|c|}
\hline \multicolumn{1}{|c|}{ Item } & Shannon index & VSS & Phospholipids & Protein & Polysaccharide \\
\hline Shannon index & - & 0.843 & 0.856 & 0.838 & 0.865 \\
\hline VSS & 0.843 & - & 0.972 & 0.978 & 0.956 \\
\hline Phospholipids & 0.856 & 0.972 & - & 0.979 & 0.993 \\
\hline Protein & 0.838 & 0.978 & 0.979 & - & 0.970 \\
\hline Polysaccharide & 0.865 & 0.956 & 0.993 & 0.970 & - \\
\hline
\end{tabular}

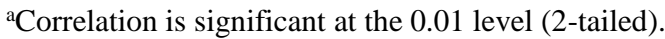

\subsection{PHYLOGENETIC ANALYSIS}

Cluster analysis of the PCR amplified fragments demonstrated that the microbial community profiles were clustered into the following four groups (Fig. 3): group 1, samples 1-4 (biofilms at the depth of $30 \mathrm{~cm}$ ), group 2, samples 5-8 (biofilms at the depth of $50 \mathrm{~cm}$ ), group 3, samples 9-12 (biofilms at the depth of $70 \mathrm{~cm}$ ), group 4, samples 13-16 (biofilms at the depth of $90 \mathrm{~cm}$ ). This suggests that the compositions of biofilms and microbial populations were similar horizontally across the SWIS and that the compositions of biofilms and microbial populations were different vertically through the SWIS.

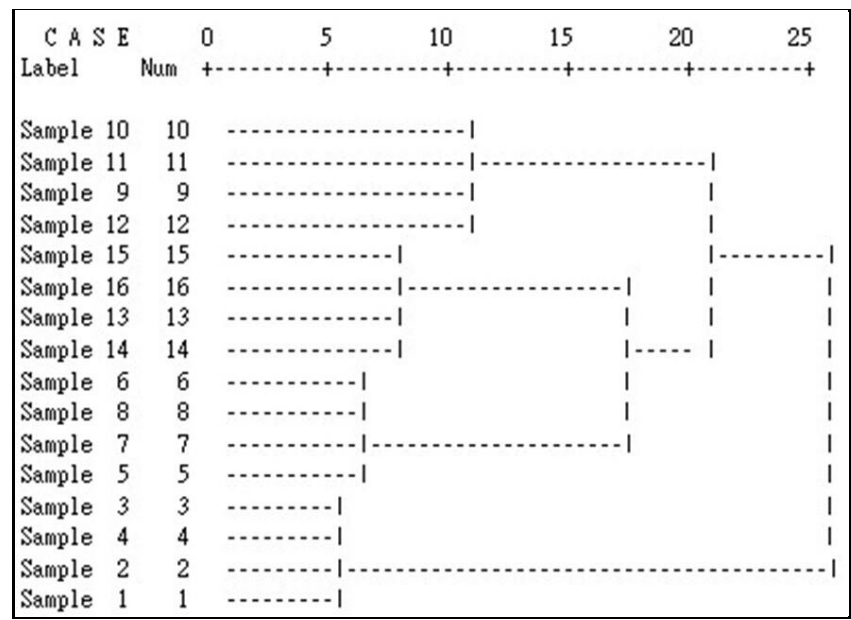

Fig. 3. Dendrogram generated by the UPGMA clustering analysis of 16S rRNA-based DGGE profile 
The clustering analysis of phylogenetic relationships based on the sequence results is shown in Fig. 3 and further confirmed the distribution of biofilms quantities, which were possibly perhaps determined by the regularity of the water stream. Given the differences observed in the bacterial profiles throughout the entire system (Fig. 1), the composition of the microbial community was examined using sequence analysis. DNA sequences of 20 bands that were clearly visible in the DGGE gels were determined. All of the identified bands exhibited similarity between 90 and $100 \%$ with previously identified gene sequences in GenBank, which are listed in Table 4.

Table 4

Bacterial 16S rRNA gene sequences obtained from SWIS

\begin{tabular}{|c|c|c|c|}
\hline $\begin{array}{l}\text { Sequenced } \\
\text { band }\end{array}$ & Closely related sequences (Accession No.) & \begin{tabular}{|c|} 
Isolated \\
environment
\end{tabular} & $\begin{array}{c}\text { Identity } \\
{[\%]}\end{array}$ \\
\hline 1 & $\begin{array}{l}\text { uncultured planctomycete clone } \\
\text { DOK_NOFERT_clone488 (DQ829420) }\end{array}$ & soil & 97 \\
\hline 2 & $\begin{array}{l}\text { uncultured Alphaproteobacteria bacterium clone } \\
\text { QEDS1CE06 (CU921713) }\end{array}$ & sludge & 100 \\
\hline 3 & uncultured Pseudomonas sp. clone L6B-307 (GU000234) & sediment & 100 \\
\hline 4 & $\begin{array}{l}\text { uncultured Chitinophagaceae bacterium clone } \\
\text { SDs2-62 (JX493492) }\end{array}$ & soil & 99 \\
\hline 5 & Bacillus nanhaiensis strain 1348 (KF218170) & sludge & 100 \\
\hline 6 & Bacillus sp. Ca7 (JX258924) & bioreactor & 99 \\
\hline 7 & $\begin{array}{l}\text { Uncultured candidate division } \\
\text { TM7 bacterium clone as1-51 (GU257584) }\end{array}$ & sludge & 94 \\
\hline 8 & Bacillus sp. STA (KC870063) & river water & 99 \\
\hline 9 & $\begin{array}{l}\text { Flavobacteriaceae bacterium enrichment culture clone } \\
\text { MT-1779 (AM292405) }\end{array}$ & petroleum & 100 \\
\hline 10 & Klebsiella oxytoca strain Y7B1 (JQ638332) & flowers & 99 \\
\hline 11 & $\begin{array}{l}\text { Uncultured Desulfuromonadales bacterium clone } \\
\text { AMHH1 (AM935554) }\end{array}$ & soil & 97 \\
\hline 12 & $\begin{array}{l}\text { Uncultured candidate division WS3 bacterium clone } \\
\text { DGGE gel band LVo-S51-17 (GU326310) }\end{array}$ & sediment & 90 \\
\hline 13 & Bdellovibrio sp. ETB (DQ302728) & soil & 100 \\
\hline 14 & Sphingosinicella sp. YJ22 (JN848800) & soil & 99 \\
\hline 15 & $\begin{array}{l}\text { Uncultured Desulfuromonas sp. clone } \\
\text { R2-69 (JX519181) }\end{array}$ & soil & 96 \\
\hline 16 & $\begin{array}{l}\text { Uncultured Chloroflexi bacterium clone } \\
\text { P-R16(JN038805) }\end{array}$ & soil & 98 \\
\hline 17 & $\begin{array}{l}\text { Uncultured Sphingobacteriales bacterium clone } \\
\text { C12_2 (JF681893) }\end{array}$ & soil & 98 \\
\hline 18 & $\begin{array}{l}\text { Uncultured Verrucomicrobia bacterium clone } \\
\text { Pas_9_2 (JF410510) }\end{array}$ & soil & 92 \\
\hline 19 & \begin{tabular}{|l|} 
Uncultured bacterium gene clone \\
07Nov1-08 (AB618359)
\end{tabular} & sewage & 100 \\
\hline 20 & Flavobacterium sp. IHB B 3314 (HM563055) & soil & 99 \\
\hline
\end{tabular}


The phylogenetic relationships based on the sequencing results are shown in Fig. 4. The dominant bacterial phylogenetic lineages derived from the biofilm samples included: Alpha-proteobacteria (bands 2 and 14), Gamma-proteobacteria (bands 3 and 10), Delta-proteobacteria (bands 11, 13, 15 and 18), Bacillus (bands 5 and 8), Flavobacteriaceae (bands 4 and 9), TM-7 (band 7) and other uncultured bacteria.

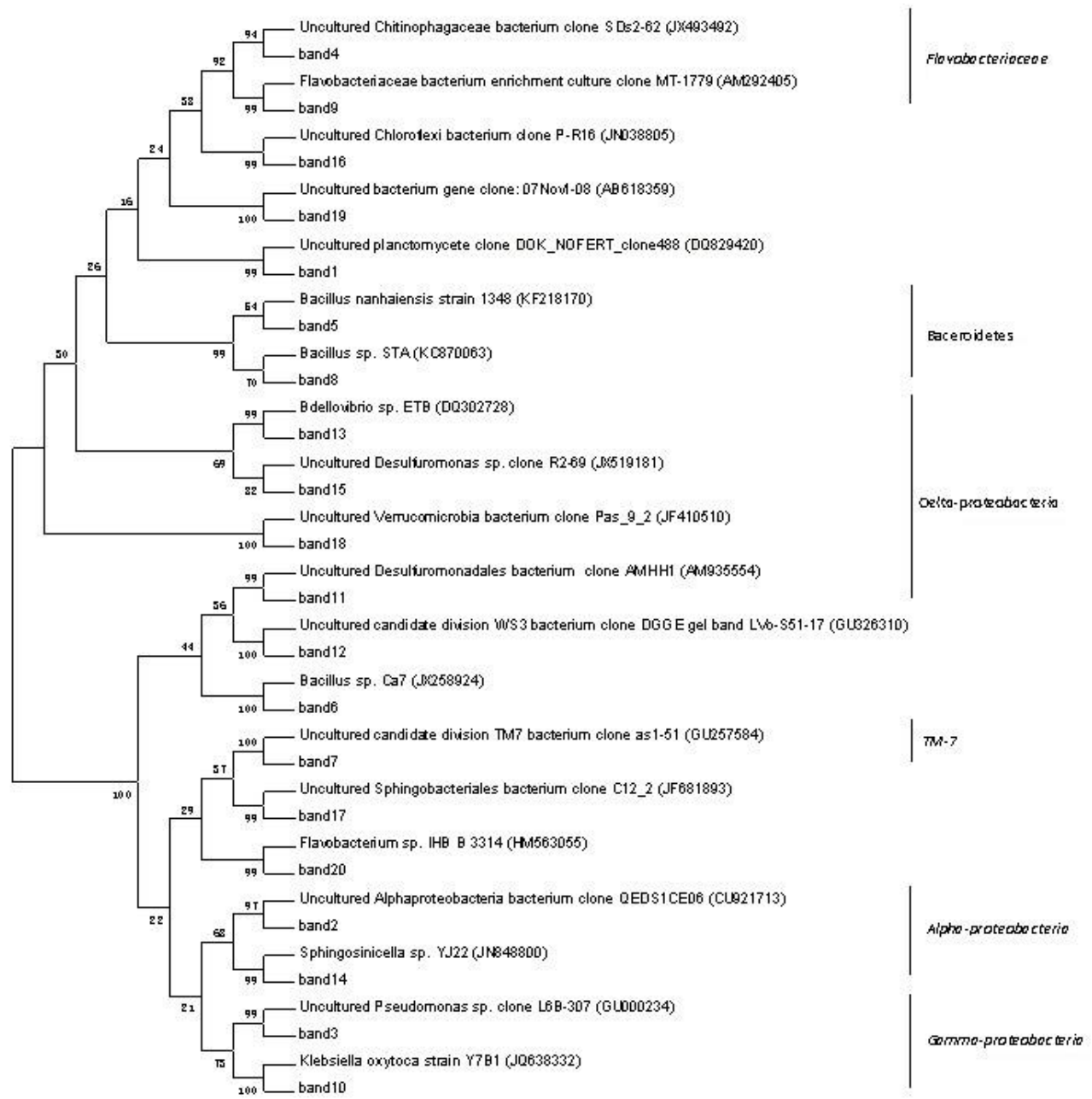

Fig. 4. Neighbor-joining phylogenetic tree of 16S rRNA gene sequences

Results indicate that Proteobacteria dominated by the Alpha-, Beta-, Gamma-and Delta-classes, are clearly the most prevalent phylum in wetlands soils. Nevertheless, due to the similar environmental characteristics found in, SWIS and wetland soils, the two environments may harbor similar microbial communities. As shown in Table 4, the 
primary functional microorganisms found in SWIS, include Alpha-, Gamma- and Deltaproteobacteria (bands 2, 3, 10, 11, 13, 14, 15 and 18). These Proteobacteria usually live in water bodies and soil, are highly adaptable to various environments, and highly active in the removal of pollution in a variety of wastewater treatment technologies. Previously, the Proteobacteria phylum was shown to dominate the bacterial communities in various types of constructed wetlands, comprising $63 \%$ of the total analyzed clones [21]. While identifying and characterizing sulfur-oxidizing bacteria in a wetland treating tannery wastewater, Aguilar et al. [22] reported bacteria isolates showing similarity to Alpha-, Beta-, Gammaproteobacteria classes, with some isolates particularly closely related to Pseudomonas stutzeri and Actinobacter sp. In addition, heterotrophic bacteria, such as Alphaproteobacteria, Bacillus, and Flavobacteriaceae were found in SWIS as dominant classes, perhaps owing to the aerobic environment, which may favor their growth.

The sequences corresponding to bands 5 (KF218170) and 8 (KC870063) showed a high degree of similarity to Bacteroidetes. Bacteria of the order Bacillus usually are found in wastewater, marine environments, sludge and biofilms. Several enzymes such as protease, lipase, etc., which hydrolyze proteins and lipids, are produced by Bacillus. Protease production is an inherent property of Bacillus species and these enzymes are generally known to be constitutively expressed or partially inducible and are controlled by numerous complex mechanisms that turn on during the transition state between exponential growth and the stationary phase [23].

Bacteria such as Aerobacter aerogenes, Mycobacterium phlei and Pseudomonas sp. are known to perform nitrification [24]. Pseudomonas sp. (band 3) in SWIS may contribute to the removal of $\mathrm{TN}$, despite the low removal efficiency. This result is consistent with the findings by Grant and Long [25], who suggested that the genera Bacillus, Micrococcus, and Pseudomonas are likely the most important in soils, while Pseudomonas, Aeromonas and Vibrio are key in the aquatic environment. Additionally, potentially denitrifying bacteria belonging to Flavobacterium sp. were found in the pilot SWIS and they may also contribute to the removal of TN. The phylogenetic tree showed close relationships between bands 4 and 9 and other uncultured denitrification bacteria.

\section{CONCLUSIONS}

For the pilot SWIS used to treat river water, the average removal efficiencies of COD, $\mathrm{TN}$ and $\mathrm{NH}_{4}{ }^{+}-\mathrm{N}$ were $43.3 \%, 28.8 \%$ and $79.6 \%$, respectively. The distribution of microbial communities and Shannon indexes corresponded well with the quantities of biofilm, characterized by VSS, phospholipids, proteins and polysaccharides. Sequencing of partial $16 \mathrm{~S}$ rRNA gene fragments revealed that the total bacterial community composition was dominated by Alphaproteobacteria, Gammaproteobacteria, Deltaproteobacteria, Pseudo- 
monas, Bacillus, Flavobacteriaceae, TM-7, and other uncultured bacteria. The phylogenetic analysis of microbial communities further confirmed the spatial distributions regularities of biofilms quantities.

\section{ACKNOWLEDGEMENTS}

The authors acknowledge the financial support from the High-Level Talents Foundation of Henan University of Technology (2012BS057), the Cultivation Project Foundation of Science and Technology Innovation Talents of Henan University of Technology (2014CXRC05) and The Key Scientific Research Projects of Henan Province institution of higher education (16B610004). We thank the State Key Laboratory of Pollution Control and Resources Reuse of China for their support. We also thank the anonymous reviewers for their careful review and valuable suggestions on the manuscript.

\section{REFERENCES}

[1] He S.B., Yan L., Kong H.N., Liu Z.M., Wu E.Y., Hu Z.B., Treatment efficiencies of constructed wetlands for eutrophic landscape river water, Pedosphere, 2007, 17 (4), 522.

[2] Yang J., Zhang L.B., Wu Y.F., Wang Y.Y., Li C., LiU W., Treatment and hydraulic performances of the NiiMi process for landscape water, J. Zhejiang Univ.-Sci. A, (Appl. Phys. Eng.), 2010, 11 (2), 132.

[3] Zhang L.B., Xing M.Y., Wu Y.F., HuANG Z.D., YANG J., Spatial distributions of biofilm properties and flow pattern in NiiMi process, Bioresource. Technol., 2011, 102, 1406.

[4] Avinash M.K., Pravin D.N., Oza G.H., Shankar H.S., Treatment of municipal wastewater using laterite-based constructed soil filter, Ecol. Eng., 2009, 35, 1051.

[5] Zou J.L., Dai Y., Sun T.H., Li Y.H., Li G.B., Li Q.Y., Effect of amended soil and hydraulic load on enhanced biological nitrogen removal in lab-scale SWIS, J. Hazard. Mater., 2009, 163, 816.

[6] Muyzer G., De WaAl E.C., UitTerLinden A.G., Profiling of complex microbial populations by denaturing gradient gel electrophoresis analysis of polymerase chain reaction-amplified genes coding for 16S rRNA, Appl. Environ. Microbiol., 1993, 59, 695.

[7] WaKelin S.A., COLlofF M.J., KoOKANA R.S., Effect of wastewater treatment plant effluent on microbial function and community structure in the sediment of a freshwater stream with variable seasonal flow, Appl. Environ. Microbiol., 2008, 74, 2659.

[8] Mulling B.T.M., Soeter A.M., Van Der Geest H.G., Admiraal W., Changes in the planktonic microbial community during residence in a surface flow constructed wetland used for tertiary wastewater treatment, Sci. Total. Environ., 2014, 466-467, 881.

[9] Liu G.H., Ye Z.F., Li H.Y., CHE R., CuI L.L., Biological treatment of hexanitrostilbene (HNS) produced wastewater using an anaerobic-aerobic immobilized microbial system, Chem. Eng. J., 2012, 213, 118.

[10] Mina I.A.P., Costa M., Matos A., Calheiros C., Castro P.M.L., Polishing domestic wastewater on a subsurface flow constructed wetland: organic matter removal and microbial monitoring, Int. J. Phytoremediat., 2011, 13 (10), 947.

[11] Wang L.M., Guo F.H., Zheng Z., Luo X.Z., Zhang J.B., Enhancement of rural domestic sewage treatment performance, and assessment of microbial community diversity and structure using tower vermifiltration, Bioresource Technol., 2011, 102 (20), 9462.

[12] Sambrook J., Frisch E.F., Maniatis T., Molecular Cloning. Laboratory Manual, 2nd Ed., Cold Spring Harbor Laboratory Press, New York 1989. 
[13] Bosshard P.P., SANtini Y., Gruter D., Stettler R., Bachofen R., Bacterial diversity and community composition in the chemocline of the meromictic alpine Lake Cadagno as revealed by $16 \mathrm{~S} r D N A$ analysis, FEMS Microbiol. Ecol., 2000, 31 (2), 173.

[14] Shannon A.E., Weaver W., The Mathematical Theory of Communication, University Illinois Press, Urbana, IL, 1963.

[15] Findlay R.H., KING G.M., WatLING L., Efficacy of phospholipid analysis in determining microbial biomass in sediments, Appl. Environ. Microbiol., 1989, 55, 2888.

[16] Zhang X.Q., Bishop P.L., Biodegradability of biofilm extracellular polymeric substances, Chemosphere, 2003, 50, 63.

[17] LiU H., FANG H.H.P., Extraction of extracellular polymeric substances (EPS) of sludges, J. Biotechnol., 2002, 95, 249.

[18] Ong S.A., UchiYAma K., InAdama D., Ishida Y., Yamagiwa K., Performance evaluation of laboratory scale up-flow constructed wetlands with different designs and emergent plants, Bioresource Technol., 2010, 101, 7239.

[19] SutherSAN S.S., Natural and Enhanced Remediation Systems, Acradis, Lewis Publisher, Washington, DC, 2002.

[20] AChaK M., Mandi L., OuAzZAni N., Removal of organic pollutants and nutrients from olive mill wastewater by a sand filter, J. Environ. Manage., 2009, 90 (8), 2771.

[21] Arroyo P., Ansola G., SÁenz De Miera L.E., Effects of substrate, vegetation and flow on arsenic and zinc removal efficiency and microbial diversity in constructed wetlands, Ecol. Eng., 2013, 51, 95.

[22] Agullar J.R.M., CABRiales J.J.P., Vega M.M., Identification and characterization of sulfur-oxidizing bacteria in an artificial wetland that treats wastewater from a tannery, Int. J. Phytoremediat., 2008, 10, 359.

[23] Beg Q.K., SAXENa R.K., GuPTA R., De-repression and subsequent induction of protease synthesis by Bacillus mojavensis under fed-batch operations, Process. Biochem., 2002, 37, 1103.

[24] Vymazal J., Removal of nutrients in various types of constructed wetlands, Sci. Total. Environ., 2007, $380,48$.

[25] GRANT W.D., Long P.E., Environmental microbiology, Blackien and Son, Glasgow 1981. 